\title{
Research on social behaviours impact evaluation of automobile recycling
}

\author{
Jia Wang ${ }^{1, *}$, Yuke $\mathrm{Li}^{1}$, Wei Pan and Zhenbiao $\mathrm{Li}^{1}$ \\ ${ }^{1}$ China Automotive Technology \& Research Center Co., Ltd., China
}

\begin{abstract}
There are different subjects in the automobile recycling behaviour, while each subject is also affected by different social behaviours, including policy guidance, social cognition, technological upgrading and environmental protection. This study uses the AHP method to analyze the influence factors of different social behaviours on different subject, so as to visually analyze the impact caused by each social behaviour. At the end of the article, some suggestions for improving automobile recycling are discussed from the perspective of social behaviours.
\end{abstract}

\section{Instruction}

In China, over the past two decades, the Chinese vehicle ownership had grown rapidly to 261.5 million in 2019. As a large number of automobiles enter into the scrapped period, how to carry out the recycling of automobile products has gradually attracted public attention. Different from other products, automobile products have more prominent social attributes and multiple groups with social attributes are involved in the process of such recycling. Therefore, studying the behaviours of different groups in the process of automobile recycling is one of the important contents of the development of automobile recycling. Different from other products, automobile products have more prominent social attributes. When the analysis on social behaviours is conducted, it is not only necessary to focus on producers or consumers as during the study. It is required to conduct research on multiple participants from the overall perspective of the entire life chain by analyzing its social behaviour from the aspects of policy guidance, social cognition, technological upgrading and environmental protection.

In the many circulation processes of automobile products, we have selected several key links that have a greater impact on product recycling behaviour. These links cover the process from production to the recycling again. The analysis on social behaviour of subjects in these links will directly affect the result of product recycling.

\section{Analysis on the social behaviour of recycling of each subjects}

\subsection{Automobile manufacturers}

Automobile manufacturers play an important role in the construction of the recycling system. The ecological design determines the degree of environmental impact and whether the back-end is easily dismantled; the disclosure of dismantling information plays a decisive role in easy and efficient dismantling by the back-end enterprises. If funds can support the construction of a back-end recycling system, it can also play a positive role.

\subsection{Dealers/repairers}

Deals/repairers have the characteristics of a mature and extensive network system, direct service to consumers and short-term storage conditions in small quantities etc. They are more suitable as recycling service outlets directly entrusted by the main body of recycling responsibility or commissioned by third-party recycling units. At the same time, repairers themselves use the inherent dominant advantages of repair technology and part selection in their operations. They have the advantages of recycling old parts and promoting the use of remanufacturing parts at the component level. Therefore, the main roles of dealers and repairers in the construction of the recycling system are as follows:

One is that both types of subject can be entrusted by producers and other recycling responsible entities or third parties in the form of recycling service outlets to carry out collection of automobiles and key parts. Usually, they can also carry out short-term storage in small quantities and then flow to long-term large-scale storage outlets or downstream comprehensive use enterprises to support the fulfillment of responsibilities in the construction of the recycling system.

Secondly, maintenance companies are driven by market interests to become an old parts recycling channel and promote the use of green parts and materials (remanufacturing parts, second-hand parts and waterbased paint etc.) in their own business activities, becoming the point to undertake recycling production-consumption cycles.

*Corresponding author: wangjia@catarc.ac.cn 


\subsection{Consumers}

Since consumers are the only natural individuals in all subjects, their social behaviour of recycling is much less restrictive than other subjects, so consumers have the lowest degree of recycling among all subjects. One is that both types of subjects can be entrusted by producers and other recycling responsible entities or third parties in the form of recycling service outlets to carry out collection of automobiles and key parts. Usually, they can also carry out short-term storage in small quantities and then flow to long-term large-scale storage outlets or downstream comprehensive use enterprises to support the fulfilment of responsibilities in the construction of the recycling system.

Regarding consumers' recycling behaviour, whether they scrap vehicles or use reused parts, the main factor is price, which has an almost direct impact. This behaviour is more tending to pure market behaviour. Therefore, the social behaviour of consumers is weak overall.

\subsection{ELVs collecting and dismantling enterprises}

Compared with other subjects, the recycling degree of ELVs collecting and dismantling enterprises is very high. Because they are involved in the recycling industry and their business entities are recycling entities, policy guidance, social awareness, technological upgrading and environmental protection have relatively large impact on the industry and it is also the subject that is most easily affected and adjusted.

\subsection{Reutilization companies}

Although this subject does not play a prominent role in constructing a recycling system, reuse and recycling can produce good environmental, social and environmental benefits.

\section{Evaluation on automobile recycling behaviourS}

\subsection{Method used}

Analytic Hierarchy Process (AHP) is a multi-objective decision-making analysis method that combines qualitative and quantitative analysis. It makes the overall decomposition of a complex system clear and transforms multi-objective and multi-criteria decision-making into multi-level and single-objective for comparison and then just perform simple mathematical operations.

The AHP can generally be used in the following three steps.

- Establish a hierarchical structure model describing system functions or characteristics: hierarchical structure is the basis for decision-makers to quantify the decisionmaking process. After in-depth analysis on the problem exposed, the factors contained in the problem are divided into different levels.

- Construct a judgment matrix: Experts compare and score each factor pairwise based on their relevant knowledge and experience to construct a judgment matrix. The value of the elements of the judgment matrix reflects people's understanding of the relative importance (or pros and cons, preferences, etc.) of each factor.

- Hierarchical single sorting and consistency check: On the basis of the constructed judgment matrix, the characteristic root of the judgment matrix A is calculated, that is, the solution $\mathrm{W}$ of $\mathrm{AW}=\mathrm{X}$, and the corresponding level at the same level can be obtained after normalization. The ranking weight of the relative importance of a factor to a factor at the previous level is called a level-single ranking. In order to carry out the consistency test on the level-single order (or judgment matrix), the consistency index $C I=\left(\lambda_{\max }-n\right) /(n-1)$ should be calculated. When the random consistency ratio $\mathrm{CR}=\mathrm{CI} / \mathrm{RI}<0.1$, the result of level-single ranking has satisfactory consistency; otherwise, the values of the elements of the judgment matrix should be adjusted.

To compare the influence of $\mathrm{n}$ factors $\mathrm{Y}=\{\mathrm{y} 1, \mathrm{y} 2, \ldots \mathrm{yn}\}$ on the same target, two factors yi and yj are took each time, a ij represents the ratio of the degree of influence of yi and yj on the target, where the value of aij is determined by Saaty's 1-9 scale method.

\subsection{Evaluation}

According to the AHP calculation process, the target comparison and weight calculation are carried out on different subjects'policy guidance (E1), social cognition

(E2) , technological upgrading(E3) and environmental protection (E4).

\subsubsection{Automobile manufacturers}

$$
\left[\begin{array}{ccccc}
- & \text { E1 } & \text { E2 } & \text { E3 } & \text { E4 } \\
\text { E1 } & 1 & 5 & 6 & 7 \\
\text { E2 } & - & 1 & 2 & 3 / 2 \\
\text { E3 } & - & - & 1 & 2 / 3 \\
\text { E4 } & - & - & - & 1
\end{array}\right]
$$

Table 1. Influencing factor coefficients of automobile manufacturers.

\begin{tabular}{|c|c|c|c|c|}
\hline & E1 & E2 & E3 & E4 \\
\hline Weight & 0.6578 & 0.1521 & 0.0839 & 0.1062 \\
\hline
\end{tabular}

Where: $\mathrm{CI}=0.0124, \mathrm{CR}=0.0098<0.1$, with satisfactory consistency.

\subsubsection{Dealers/repairers}

$$
\left[\begin{array}{ccccc}
- & \text { E1 } & \text { E2 } & \text { E3 } & \text { E4 } \\
\text { E1 } & 1 & 9 & 5 & 8 \\
\text { E2 } & - & 1 & 1 / 2 & 1 / 3 \\
\text { E3 } & - & - & 1 & 2 \\
\text { E4 } & - & - & - & 1
\end{array}\right]
$$


Table 2. Influencing factor coefficients of dealers/repairers.

\begin{tabular}{|c|c|c|c|c|}
\hline & E1 & E2 & E3 & E4 \\
\hline Weight & 0.6883 & 0.0583 & 0.1494 & 0.1040 \\
\hline
\end{tabular}

Where: $\mathrm{CI}=0.0440, \mathrm{CR}=0.0349<0.1$, with satisfactory consistency.

\subsubsection{Consumers}

$$
\left[\begin{array}{ccccc}
- & \text { E1 } & \text { E2 } & \text { E3 } & \text { E4 } \\
\text { E1 } & 1 & 7 & 5 & 6 \\
\text { E2 } & - & 1 & 1 / 2 & 1 \\
\text { E3 } & - & - & 1 & 4 \\
\text { E4 } & - & - & - & 1
\end{array}\right]
$$

Table 3. Influencing factor coefficients of Consumers.

\begin{tabular}{|c|c|c|c|c|}
\hline & E1 & E2 & E3 & E4 \\
\hline Weight & 0.6452 & 0.0876 & 0.1906 & 0.0766 \\
\hline
\end{tabular}

Where: $\mathrm{CI}=0.0471, \mathrm{CR}=0.0374<0.1$, with satisfactory consistency.

\subsubsection{ELVs collecting and dismantling enterprises}

$$
\left[\begin{array}{ccccc}
- & \text { E1 } & \text { E2 } & \text { E3 } & \text { E4 } \\
\text { E1 } & 1 & 8 & 2 & 4 \\
\text { E2 } & - & 1 & 1 / 3 & 1 / 2 \\
\text { E3 } & - & - & 1 & 2 \\
\text { E4 } & - & - & - & 1
\end{array}\right]
$$

Table 4. Influencing factor coefficients of ELVs collecting and dismantling enterprise

\begin{tabular}{|c|c|c|c|c|}
\hline & E1 & E2 & E3 & E4 \\
\hline Weight & 0.5407 & 0.0726 & 0.2516 & 0.1352 \\
\hline
\end{tabular}

Where: $\mathrm{CI}=0.0035, \mathrm{CR}=0.0027<0.1$, with satisfactory consistency.

\subsubsection{Reutilization enterprises}

$$
\left[\begin{array}{ccccc}
- & \text { E1 } & \text { E2 } & \text { E3 } & \text { E4 } \\
\text { E1 } & 1 & 3 & 1 / 2 & 1 \\
\text { E2 } & - & 1 & 1 / 4 & 1 \\
\text { E3 } & - & - & 1 & 3 \\
\text { E4 } & - & - & - & 1
\end{array}\right]
$$

Table 5. Influencing factor coefficients of automobile manufacturers.

\begin{tabular}{|c|c|c|c|c|}
\hline & E1 & E2 & E3 & E4 \\
\hline Weight & 0.2397 & 0.1164 & 0.4794 & 0.1646 \\
\hline
\end{tabular}

Where: $\mathrm{CI}=0.0341, \mathrm{CR}=0.0271<0.1$, with satisfactory consistency.
Based on the above, we can get the comprehensive influence of each influencing factor on the subject, as shown in Figure 1.

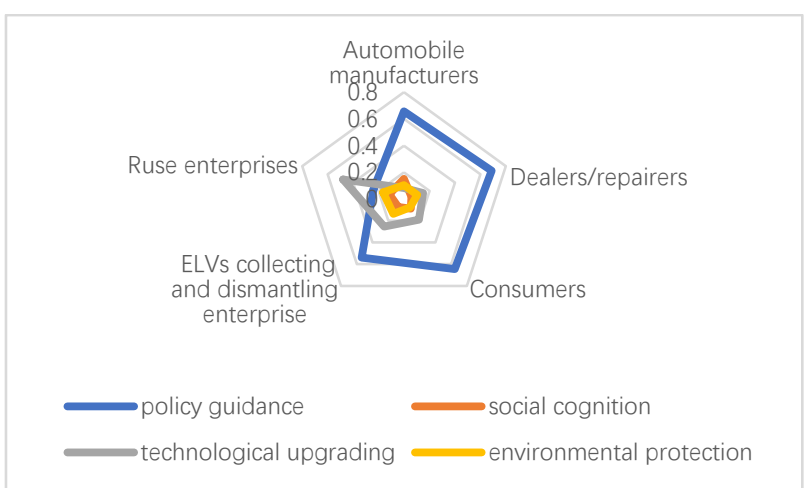

Fig. 1. Radar chart of influence factors of each subjects.

\section{Discussion}

\subsection{Policy guidance is an important influencing factor on each subject}

The trend of policy guidance is still very obvious among various factors. In the case of goal-oriented and measure incentives, the influence of policy guidance on various subject is particularly important. For the subject that do not generate economic value, such as consumers and dealers/repairers, policy guidance is the main influence on their participation in recycling behaviour. Although other factors also have an impact coefficient, but if there is no policy guidance, the coefficient of these factors will undoubtedly drop.

Policy guidance is not only the most important factor among the various factors, but also affects the coefficients of other factors. It has a decisive and fundamental role among the four social behaviour factors.

\subsection{Social cognition is gradually improved among all subjects}

Social cognition is actually the cognition of social responsibility of the group in terms of recycling. That is to say, when the group realizes its own value and creates profits, it must also bear the social and environmental responsibilities for recycling and contribute to the sustainable development of society.

In the past, it was generally believed that social cognition itself had no direct relationship with the improvement of economic value of a company, while it might even reduce revenue due to the increase in company's costs. However, with the development of China's economy and society, social responsibility has gradually become a focus and hot spot, while more and more companies are called upon to attach importance to corporate social responsibility. At the same time, it is found that the practice of corporate social responsibility has a significant impact on the economic performance, social performance and environmental performance of enterprises. Therefore, various groups gradually increase the attention to social cognition, especially automobile 
manufacturers play a leading role in the entire automobile industry chain. Social cognition has become an important consideration factor affecting the value of automobile brands.

\subsection{Environmental protection has not yet become the dominant driver.}

Environmental protection is the most basic requirement of China for all groups. And at the same time, this stage is also a very important period in the history of China's development of environmental protection. During this period, China's environmental protection has undergone major reforms and adjustments in terms of management strategy, management system, management thinking and management objectives, while environmental protection has entered into a substantive stage. However, there is one similarity between environmental protection and social cognition, that is, it is not directly driven by the market. In addition to the self-consciousness of the group, it can only rely on the indirect guidance of economic value or mandatory requirements of policies.

\subsection{Technological upgrading is gearing up.}

In the entire automobile life cycle industry chain, the recycling links at the end have always been at a low level of technology. Due to the low profits, ELVs collecting and dismantling enterprises have been in an extensive dismantling mode. The company's income mainly relies on the sale of scrapped steel, so the direct factor is the number of cars collected rather than the technical level. For manufacturing enterprises, improvement in the recycling rate of automobiles is one of the main evaluation indicators for the implementation of producer responsibility. However, China's extended producer responsibility system has not been fully implemented, so manufacturing enterprises have not paid enough attention to it.

\section{Conclusion}

Automobile products are relatively special products. It has a long industrial chain and covers a wide range of areas. In terms of recycling, there are also many types of entities involved, including manufacturing companies, insurance companies, second-hand parts circulation companies, ELVs collecting and dismantling enterprises , reutilization enterprises and consumers, etc. Therefore, the joint efforts of all participants are required to build an effective recycling system. At the same time, the establishment of the recycling system is also closely related to the awareness of social resource utilization and it is necessary to gradually enhance the overall awareness of society under the influence of daily behaviour.

In the entire recycling system, manufacturing enterprises and ELVs collecting and dismantling enterprises are two important subjects. Under the current situation in our country, it is urgent to implement the extended producer responsibility system and establish a producer-led recycling system as soon as possible. At the same time, on the recycling side, technological upgrading should be accelerated through dismantling and reuse to improve resource reuse rate and reduce potential safety and environmental hazards.

This work was supported by National Key Research and Development Program of China Solid Waste Resource Utilization Special Project Automobile Products and Typical Parts Lifecycle Traceability System Design and Demonstration Application Research (2018YFC1902704) and CATARC Soft Science Research Project Study on the Evaluation of Compulsory Scrapping Index of Motor vehicles and the Optimization of Management system 20213204.

\section{References}

1. J. Wang, Y. Li, W. Pan. Analysis on policy environment of China's ELV recycling industry. Automotive industry research [J]. 2015 (12): 34-36

2. M. Chen, F. Zhang,. End-of-Life vehicle recovery in china: Consideration and innovation following the EU ELV directive[J]. JOM, 61(2009): 45-52

3. Development Report on Recycling and Dismantling of End-of-Life Motor Vehicles in China [R]. Beijing: China material recycling association, 2020:1-4

4. S. Wang, G. Fan, J. Yu. The Trace and Features of EPR in ELV Recycling System:Comparison of International Trend[C]. Proceedings of the 28th Annual Conference of Japan Society of Material Cycles and Waste Management, 2017 